\title{
Higher, faster, stronger: The effect of dynamic stimuli on response preparation and CNV amplitude
}

Citation for published version (APA):

Linssen, A. M. W., Sambeth, A., Riedel, W. J., \& Vuurman, E. F. P. M. (2013). Higher, faster, stronger: The effect of dynamic stimuli on response preparation and CNV amplitude. Behavioural Brain Research, 237, 308-312. https://doi.org/10.1016/j.bbr.2012.09.050

Document status and date:

Published: 15/01/2013

DOI:

10.1016/j.bbr.2012.09.050

Document Version:

Publisher's PDF, also known as Version of record

Document license:

Taverne

Please check the document version of this publication:

- A submitted manuscript is the version of the article upon submission and before peer-review. There can be important differences between the submitted version and the official published version of record.

People interested in the research are advised to contact the author for the final version of the publication, or visit the DOI to the publisher's website.

- The final author version and the galley proof are versions of the publication after peer review.

- The final published version features the final layout of the paper including the volume, issue and page numbers.

Link to publication

\footnotetext{
General rights rights.

- You may freely distribute the URL identifying the publication in the public portal. please follow below link for the End User Agreement:

www.umlib.nl/taverne-license

Take down policy

If you believe that this document breaches copyright please contact us at:

repository@maastrichtuniversity.nl

providing details and we will investigate your claim.
}

Copyright and moral rights for the publications made accessible in the public portal are retained by the authors and/or other copyright owners and it is a condition of accessing publications that users recognise and abide by the legal requirements associated with these

- Users may download and print one copy of any publication from the public portal for the purpose of private study or research.

- You may not further distribute the material or use it for any profit-making activity or commercial gain

If the publication is distributed under the terms of Article $25 \mathrm{fa}$ of the Dutch Copyright Act, indicated by the "Taverne" license above, 
Research report

\title{
Higher, faster, stronger: The effect of dynamic stimuli on response preparation and CNV amplitude
}

\author{
A.M.W. Linssen*, A. Sambeth, W.J. Riedel, E.F.P.M. Vuurman \\ Dept. Neuropsychology \&' Psychopharmacology, Faculty of Psychology and Neuroscience, Maastricht University, PO Box 616, 6200 MD, Maastricht, The Netherlands
}

\section{H I G H L I G H T S}

- Two new response preparation tasks were designed to gain an optimal CNV.

- Dynamic stimuli were used in a regular and a Go/No-go version of the task.

- Response times increased as the probability of response requirement decreased.

- CNV amplitude was larger when probability of response requirement was higher.

- The dynamic task promotes response preparation.

\section{A R T I C L E I N F O}

\section{Article history:}

Received 11 May 2012

Received in revised form

25 September 2012

Accepted 28 September 2012

Available online 4 October 2012

\section{Keywords:}

Electroencephalography

Contingent negative variation

Response preparation

\begin{abstract}
A B S T R A C T
The contingent negative variation (CNV) is a slow negative shift in the electroencephalogram (EEG), observed during response preparation. To optimalize the CNV paradigm, this study developed a task using dynamic stimuli and next combined this task with a Go/No-go test. In the first experiment, 19 healthy volunteers were subjected to the classic Traffic light (TL) task and the new dynamic Lines task. In the Lines task, response time was faster and CNV amplitude was larger compared to the TL task. In the second experiment, 20 healthy participants were tested on a Go/No-go version of the Lines task. Response times increased as the probability of response requirement decreased. CNV amplitude was larger when probability of response requirement was higher. In conclusion, the dynamic task promotes response preparation. The new tasks may be especially valuable in groups with attention difficulties (i.e. elderly or ADHD patients).
\end{abstract}

(c) 2012 Elsevier B.V. All rights reserved.

\section{Introduction}

The contingent negative variation $(\mathrm{CNV})$ is a slow negative shift in the electroencephalogram (EEG) which can be observed during response preparation to an anticipated stimulus [1-3]. Since its discovery by Walter in 1964 it has been studied extensively [4]. The amplitude of the CNV has been shown to increase with increased motivation and attention [2,5]. The diversity of tasks that are employed to evoke the CNV reflects the variety of applications of the CNV, ranging from fundamental research to studies in different clinical groups. The CNV may be affected in patients with attention deficit/hyperactivity disorder (ADHD), Alzheimer's disease (AD) and Parkinson's disease (PD) and can also

\footnotetext{
* Corresponding author. Tel.: +31 433881530; fax: +31 433884560

E-mail addresses: anke.linssen@maastrichtuniversity.nl (A.M.W. Linssen), anke.sambeth@maastrichtuniversity.nl

(A. Sambeth),w.riedel@maastrichtuniversity.nl (W.J. Riedel),

eric.vuurman@maastrichtuniversity.nl (E.F.P.M. Vuurman).
}

be used to evaluate drug effects [6-11]. Hence, the CNV could potentially be used to screen for normalization of CNV amplitude in neuropsychiatric patients in response to treatment. The current paper describes the development of instruments that could eventually be applied as a screening tool, seeking to implement previously acquired knowledge about the CNV to optimize the CNV paradigm and reliably produce large CNVs. To this end, new response preparation tasks were designed to promote motivation and attention during task performance and induce larger CNVs and faster responses compared to conventional response preparation tasks.

Two components can be distinguished in the CNV, an early and a late component or wave, or the 'O-wave' and 'E-wave', referring to orientation and expectancy [12,13]. The early wave increases with stimulus intensity, is enhanced when auditory warning stimuli are used, and habituates over trials, all of which support that it reflects an orienting response [14-16]. It has been proposed that the late $\mathrm{CNV}$ is a composite of a readiness potential and stimulus preceding negativity $[3,17]$, reflecting motor preparation and stimulus anticipation [18]. 
The early CNV has its cortical origin in prefrontal supplementary sensorimotor areas; the late wave in prefrontal, supplementary sensorimotor, primary somatosensory, primary motor, temporal and occipital areas [19]. Hence, early CNV has been found to be least prominent at the Pz electrode location whereas the late wave was hardly visible at the Fz electrode $[13,20]$.

The classic CNV task constitutes a warning stimulus (S1) followed by an imperative stimulus (S2) after a fixed and known interval. Stimulus manipulations differentially affect the early and late CNV waves [21]. For example, the amplitude of the early CNV wave increases with increased warning signal duration [13], whereas the amplitude of the late wave increases if the imperative stimulus contains information about the required response [3]. In a Go/No-go paradigm, in which the warning stimulus gives information about the required response, the warning stimulus may affect both early and late CNV [22-24].

In order for the response preparation task to be used as a screening tool, it needs to reliably evoke a CNV. Since CNV amplitude has been reported to be decreased in clinical groups such as PD and ADHD patients [7,25], a successful task should induce large CNV waves. To acquire an optimal CNV, a substantial number of trials have to be recorded in which the subjects have to produce speeded responses. Furthermore, the interval between S1 and S2 needs to be rather long (3-4s) in order to observe both an early and a late wave [26]. This is potentially problematic, as especially the elderly, children, AD and ADHD patients may suffer from loss of focused attention and possibly fail to show an anticipatory response $[8,27]$. In this study, an attempt was made to overcome these problems by developing new tasks using stimuli that promote response anticipation.

In a conventional response preparation task, using static stimuli, there is a 4-s window in which nothing happens and attention is easily diverted away from the task. Therefore, it was decided a new task should employ moving stimuli. We designed a task in which participants view two lines moving toward each other that intersect after $4 \mathrm{~s}$, to which the participant has to respond by a button press. In this 'Lines task' participants can continuously track the lines during the interval between $\mathrm{S} 1$ (the appearance of the lines) and S2 (the crossing of the lines). A major advantage of this task as opposed to static tasks or dynamic tasks in which the timing of S2 is varied [28] is that the movement of the lines allows very precise estimation of the occurrence of the imperative stimulus which was expected to enhance CNV amplitude and speed responses. An additional advantage of the Lines task could be that participants may feel more encouraged to provide a quick response and hence, maintain focused attention. In experiment 1 , we tested the hypothesis that the 'Lines task' would lead to improved response preparation as indicated by an increase in late CNV amplitude and faster response times when compared to a standard CNV task using static stimuli.

Once efficacy of this task was established, the task was further adapted, creating a Go/No-go task. Within a Go/No-Go task, it is uncertain whether a response will be required. We were interested to see how this would affect the CNV. Moreover, in contrast with the $\mathrm{S} 2$ in the Lines task, the imperative stimulus in our Go/No-Go task carries information as to whether a response has to be given or not, an aspect that may affect not only the late, but also the early CNV wave. Both early and late CNV wave, as induced by the Go/No-go task were studied in experiment 2 .

\section{Experiment 1}

\subsection{Method}

\subsubsection{Participants}

Nineteen healthy male volunteers (mean age $=23.4, \mathrm{SD}=5.4$ ) were selected and paid to participate. They were all right handed. Participants were recruited by means of advertisement posters in university buildings and advertisements in the
Table 1

Mean amplitudes (SEM) of the CNV for 3 electrode positions of experiment 1.

\begin{tabular}{llr}
\hline Electrode & Stoplight & \multicolumn{1}{c}{ Lines } \\
\hline C3 & $-5.12(0.60)$ & $-9.29(1.39)$ \\
Cz & $-5.79(0.81)$ & $-11.07(1.63)$ \\
C4 & $-4.62(0.54)$ & $-8.60(1.41)$ \\
\hline
\end{tabular}

university newspaper. All subjects gave written informed consent. The study was part of a larger study which was approved by the ethical committee of Maastricht University and conducted in accordance with the Declaration of Helsinki 1975, revised Seoul, 2008.

\subsubsection{Procedure}

Participants were invited into the lab at either 8:00 or 8:30 AM. EEG was measured using eleven electrodes placed on the scalp, according to the 10-20 system (Jasper, 1958) at the Fz, F3, F4, Cz, C3, C4, Pz, P3, P4, O1 and $\mathrm{O} 2$ electrode positions. Electrodes placed on the left and right mastoid served as reference channels. The ground electrode was placed at the AFz location on the forehead. An electrooculogram (EOG) was measured bipolarly above and below the right eye and horizontally next the left and right eye. Impedances were kept below $5 \mathrm{k} \Omega$. Data were sampled at $1000 \mathrm{~Hz}$ and filtered online between 0.05 and $100 \mathrm{~Hz}$. Participants received task instructions both orally and on the computer screen. They performed two different tasks: first a standard response preparation task, the 'TL task' (static task) immediately followed by the 'Lines task' (dynamic task).

2.1.2.1. CNV Traffic light task. In the CNV Traffic light (TL) task, participants watched the computer screen and were presented with a filled red circle (S1) on a black background. After $4 \mathrm{~s}$, the red circle turned green (S2). Subjects were instructed to respond to the green circle by pressing a button with the index finger of the dominant (right) hand on a table mounted response box as fast as they could. The test consisted of 32 trials.

2.1.2.2. CNV Lines task. In the CNV Lines task, $\mathrm{S} 1$ was the appearance of two red line drawings. The Lines were oriented at a $90^{\circ}$ angle of each other and after appearing both moved diagonally upwards to the center of the screen (forming and inverted V). The full movement of the lines spanned approximately $10 \mathrm{~cm}^{2}$. Participants were instructed to fixate on the center of the screen between trials. This was indicated by a fixation cross, which disappeared at the start of the trial. After $4 \mathrm{~s}$, the Lines crossed and turned green (S2). At this moment, participants pressed a response button with the index finger of the dominant (right) hand as fast as possible. The visual angle between the fixation cross and the location where the lines crossed was $0.026^{\circ}$. The test consisted of 25 trials.

\subsubsection{Data analysis}

EEG data were screened for artifacts offline, corrected for eye movements [29] and a low pass filter of $10 \mathrm{~Hz}$ was applied. Event-related potentials were extracted by stimulus locked averaging of epochs starting $100 \mathrm{~ms}$ before S1 and ending $1000 \mathrm{~ms}$ after S2. A baseline correction was applied on the whole epoch, using the $100 \mathrm{~ms}$ interval preceding S1 as reference. Late CNV amplitude was calculated by averaging the amplitude over the last 100 milliseconds before S2. Since the CNV amplitude was expected to be maximal at the central electrodes analyses was restricted to $\mathrm{Cz}$, $\mathrm{C} 3$ and $\mathrm{C} 4$ electrodes.

Reaction time and EEG data were analyzed using repeated measures analysis of variance (ANOVA) with the within subjects factor task which had two levels, namely the TL task and the Lines task. For the amplitude data there was an additional within subjects factor electrode which had 3 levels $(\mathrm{C} 3, \mathrm{Cz}, \mathrm{C} 4)$. The behavioral dependent variable was response time (in $\mathrm{ms}$ ) of correct responses (i.e. excluding responses before the lines changed color). The effects were evaluated using Greenhouse-Geisser correction and were considered significant at $p<0.05$. Where necessary, the Bonferroni correction was applied. In the case of a significant main effect, post hoc pairwise comparisons were conducted. Interaction effects were analyzed post hoc by conducting additional repeated measures ANOVAs, including only those factors that were involved in the interaction. Only significant effects are reported.

\subsection{Results}

Average response time in the Lines task was faster than in the standard TL task $\left(M_{\mathrm{TL}}=247 \mathrm{~ms}, M_{\text {Lines }}=59 \mathrm{~ms} ; F_{1.0,0,18.00}=932.752\right.$, $p<0.001$ ).

Averaged CNV waves recorded at the $\mathrm{Cz}$ electrode during performance of the TL task and the Lines task are shown in Fig. 1. Mean CNV amplitudes at all electrodes are presented in Table 1. Amplitude of the CNV was significantly affected by both task $\left(F_{1.00,18.00}=8.653, p<0.05\right)$ and electrode position 


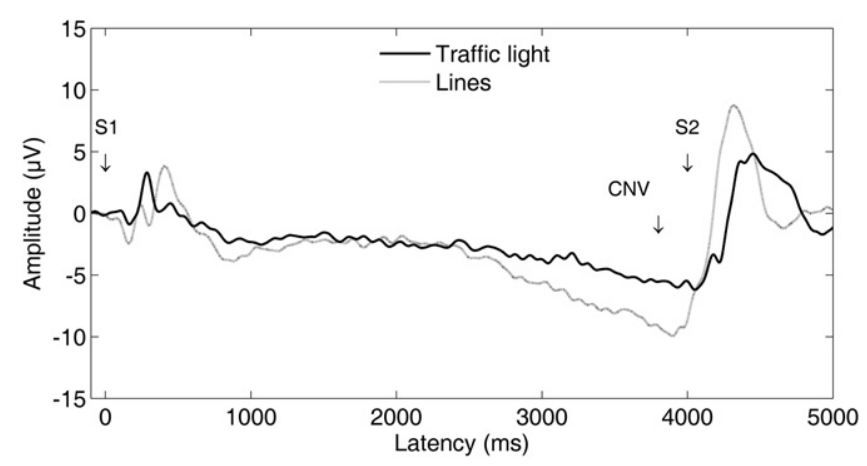

Fig. 1. Grand ERPs showing CNV waves measured at $\mathrm{Cz}$ during the TL and Lines tasks.

$\left(F_{1.77,31.84}=8.648, p<0.001\right)$. Amplitude was larger in the Lines task than in the TL task. Pairwise comparisons for electrode positions indicated that $\mathrm{CNV}$ amplitude was largest at $\mathrm{Cz}$, smallest at $\mathrm{C4}$, and intermediate at $\mathrm{C} 3$.

\section{Experiment 2}

\subsection{Method}

\subsubsection{Participants}

Twenty healthy participants ( 10 male and 10 female, mean age $=23.0, S D=1.2$ ) were selected and paid to participate. All but one were right handed. They were recruited by means of advertisement posters at Maastricht University. This study was conducted as a pilot of a larger study which was approved by the ethical committee of Maastricht University and conducted in accordance with the Declaration of Helsinki 1975, revised Seoul, 2008.

\subsubsection{Procedure}

Participants were invited into the lab at either 9:00 or 11:00 AM. They signed informed consent and filled out a brief questionnaire assessing demographic variables. Next, they were prepared for EEG measurement. An electrode cap was placed which contained 32 electrodes at locations in accordance with the international 10-20 system (Jasper, 1958). Otherwise, EEG measurement procedures were identical to those in experiment 1.

Participants received task instructions both orally and on the computer screen. The task was carried out in two identical parts each containing 144 trials and lasting approximately $18 \mathrm{~min}$, with a $5 \mathrm{~min}$ break in between. The warning stimulus, S1, was the appearance of two red line drawings at the bottom left and right hand corner. The Lines were oriented at a $90^{\circ}$ angle of each other and after appearing both moved diagonally upwards to the center of the screen (forming and inverted V). The full movement of the lines spanned approximately $10 \mathrm{~cm}^{2}$. Participants were instructed to focus on the fixation cross at the center of the screen. After $4 \mathrm{~s}$, the Lines crossed (S2). At this moment, participants pressed a response button with the index finger of the dominant (right) hand as fast as possible, but only if the Lines turned green (Go trial) at the moment they crossed. If the Lines remained red, participants should withhold the response (No-go trial). The chance that a trial was a Go trial was indicated at S1 by a percentage and could be either 20,50 or $100 \%$ (randomized per block). For each of these percentages, there were 36 Go trials. Consequently, a total of $36100 \%$ trials was presented, whereas for the $50 \%$ trials, there were 72 trials ( 36 go and 36 No-go) and for the 20\% trials, 180 trials were present ( 36 go and 144 No-go).

\subsubsection{Data analysis}

EEG data were screened for artifacts offline corrected for eye movements [29] and a low pass filter of $10 \mathrm{~Hz}$ was applied. Event-related potentials were extracted by stimulus locked averaging of epochs starting $100 \mathrm{~ms}$ before $\mathrm{S} 1$ and ending $4800 \mathrm{~ms}$ after S2. A baseline correction was applied on the whole epoch, using the $100 \mathrm{~ms}$ interval preceding S1 as reference. Early CNV was determined as the average amplitude between 750 and $1200 \mathrm{~ms}$ after S1 relative to baseline. Late CNV was determined as the average amplitude between 3600 and $4000 \mathrm{~ms}$ after S1. For both waves, mean amplitudes were analyzed for F3, Fz, F4, FC3, FCz, FC4, C3, Cz and C4. Only correct trials were taken into account.

Behavioral and EEG data were analyzed using repeated measures analysis of variance (ANOVA) with the within subjects factor trial type which had three levels, namely the 20,50 and $100 \%$ trials. For the amplitude data there was an additional within subjects factor electrode which had 9 levels (F3, Fz, F4, FC3, FCz, FC4, C3, Cz, C4). Behavioral dependent variables were response time (in ms) of correct responses (i.e. excluding prepotent responses and responses to No-go trials), hit rate, and false alarm rate. As in experiment 1 , the effects were evaluated using Greenhouse-Geisser

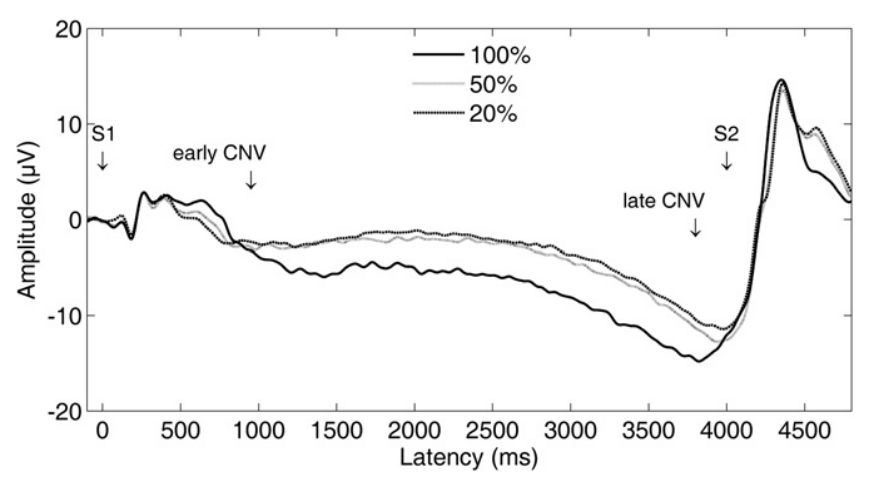

Fig. 2. Grand ERPs showing CNV waves measured at $\mathrm{Cz}$ during each of the three trial types with $100 \%, 50 \%$ and $20 \%$ chance on a go trial.

correction and were considered significant at $p<0.05$. Where necessary, the Bonferroni correction was applied. In the case of a significant main effect, post hoc pairwise comparisons were conducted. Interaction effects were analyzed post hoc by conducting additional repeated measures ANOVAs, including only those factors that were involved in the interaction. Only significant effects are reported.

\subsection{Results}

\subsubsection{Task performance}

Means and standard errors of measurement for the main outcome variables including response time, hit rate and false alarm rate for each trial type are presented in Table 2 . There was a significant main effect of trial type on response time $\left(F_{1.11,21.24}=357.243\right.$, $p<0.001)$. Pairwise comparisons revealed that response times increased as the probability of response requirement decreased. In other words, the more unsure participants were about whether they would have to respond, the slower they responded. Hit rate was smaller in the $100 \%$ Go trials compared to the 20 and $50 \%$ Go trials, due to premature responding in the $100 \%$ Go trials $\left(F_{2,38}=35.119, p<0.001\right)$. False alarm rate was larger for the $50 \%$ No-go trials than for $20 \%$ No-go trials $\left(F_{1,19}=9.824, p<0.01\right)$.

\subsubsection{Amplitude data}

Averaged $\mathrm{CNV}$ waves recorded at the $\mathrm{Cz}$ electrode during performance of the Go/No-go task are shown in Fig. 2. Mean early and late CNV amplitudes at all electrodes are presented in Tables 3 and 4 respectively.

3.2.2.1. Early CNV wave. A main effect of electrode position $\left(F_{1.52,28.88}=4.685, p<0.05\right)$ indicated that the amplitude of the early CNV differed between electrode positions. Pairwise comparisons revealed that amplitude was larger at $\mathrm{FCz}$ compared to F4 and C4, and larger at $\mathrm{Cz}$ than at $\mathrm{C} 4$. When amplitudes were analyzed for each electrode separately, a main effect of trial type was found for the frontal electrodes (F3: $F_{2,38}=4.801, p<0.05$, Fz: $F_{2,38}=7.720$, $\left.p<0.01, \mathrm{~F} 4: F_{1.33,25.19}=4.617, p<0.05\right)$ and FC3 $\left(F_{1.53,29.13}=3.801\right.$, $p<0.05)$ but not for the other 5 electrodes. Pairwise comparisons showed that the amplitude was larger when requirement of response probability was $100 \%$ compared to $50 \%$ at F3, Fz and F4 and compared to $20 \%$ at Fz. For FC3 pairwise comparisons revealed no significant results.

3.2.2.2. Late $C N V$ wave. Amplitude of the late $C N V$ was significantly affected by both trial type $\left(F_{1.49,28.25}=4.638, p<0.05\right)$ and electrode position $\left(F_{2.64,50.15}=21.012, p<0.001\right)$. In addition, an interaction between these two factors was observed $\left(F_{4.79,90.95}=2.604, p<05\right)$. Pairwise comparisons revealed no significant differences for the trial types. For the electrode positions, pairwise comparisons indicated that the late CNV amplitude generally was smallest for the 
Table 2

Mean (SEM) response times, hit rate and false alarm rate for experiment 2.

\begin{tabular}{|c|c|c|c|c|c|}
\hline & $100 \%$ Go & $50 \%$ Go & $50 \%$ No-go & $20 \%$ Go & $20 \%$ No-go \\
\hline Response time & $103(10)$ & $286(4)$ & & $301(5)$ & \\
\hline Hit rate & $0.93(0.01)$ & $1.00(0.00)$ & & $1.00(0.00)$ & \\
\hline False alarm rate & & & $0.024(0.006)$ & & $0.007(0.002)$ \\
\hline
\end{tabular}

Table 3

Mean amplitudes (SEM) of the early CNV for the different trial types in the 9 electrode positions.

\begin{tabular}{|c|c|c|c|c|c|}
\hline Electrode & $F$ & df & $100 \%$ & $50 \%$ & $20 \%$ \\
\hline F3 & $4.801^{*}$ & $1.78,33.75$ & $-2.80(1.03)$ & $-1.35(1.01)$ & $-1.45(0.75)$ \\
\hline $\mathrm{Fz}$ & $7.720^{*}$ & $1.56,29.62$ & $-3.94(0.78)$ & $-2.28(0.73)$ & $-1.89(0.68)$ \\
\hline $\mathrm{F} 4$ & $4.617^{*}$ & $1.33,26.19$ & $-1.64(0.73)$ & $-0.07(0.72)$ & $-0.01(0.84)$ \\
\hline FC3 & $3.801^{*}$ & $1.53,29.13$ & $-3.61(1.01)$ & $-2.33(0.88)$ & $-2.21(0.66)$ \\
\hline $\mathrm{FCz}$ & 2.206 & $1.35,25.67$ & $-1.93(0.82)$ & $-0.99(0.75)$ & $-0.57(0.80)$ \\
\hline FC4 & 3.375 & $1.55,29.40$ & $-4.29(0.95)$ & $-3.07(0.86)$ & $-2.56(0.71)$ \\
\hline $\mathrm{C} 3$ & 1.126 & $1.46,27.65$ & $-2.77(0.98)$ & $-1.96(0.78)$ & $-1.93(0.54)$ \\
\hline $\mathrm{Cz}$ & 1.180 & $1.52,28.90$ & $-3.54(0.95)$ & $-2.83(0.82)$ & $-2.42(0.63)$ \\
\hline $\mathrm{C} 4$ & 0.512 & $1.42,26.89$ & $-1.31(0.81)$ & $-0.89(0.68)$ & $-0.61(0.67)$ \\
\hline
\end{tabular}

$p<0.05$.

most frontal electrodes and increased as the position was more central. However, not all pairwise comparisons were significant.

To further explore the interaction between electrode position and trial type, the effect of trial type was analyzed for each electrode position separately (see Table 4). It was shown that amplitude increased with increasing probability of response requirement at $\mathrm{Cz}, \mathrm{C} 3, \mathrm{C} 4, \mathrm{FC}, \mathrm{FC} 3$ and FC4 and F4 (although this was only significant for the $100 \%$ vs. the $20 \%$ trials). This effect was most significant at the central electrode positions, less significant for the frontocentral positions and non-significant for two out of three frontal positions.

In order to see if the late CNV was lateralized, a comparison was made between electrode positions that were contralateral vs. ipsilateral to the response finger. This revealed a trend suggesting that the late CNV was slightly larger at the central electrode contralateral to the response finger ( $\mathrm{C} 3$ in most participants) compared to ipsilateral central electrode (C4 in most participants, $F_{1,19}=3.409$, $p<0.10)$.

\section{Discussion}

The current study aimed to develop response preparation tasks producing CNVs that could be potentially useful as a screening tool. We showed enhanced response preparation in a newly developed task applying dynamic stimuli in relation to a task with static stimuli, as was indicated by larger CNV amplitude and faster response times. In a second experiment we tested whether this effect persisted if the task was adjusted to a Go/No-go format. The probability that participants had to respond (Go trials) differed between the trials. As predicted this manipulation differentially affected amplitudes of the early and late CNV waves and response times. The smaller the probability of response requirement, the smaller the CNV amplitudes and the slower participants responded.

The finding that participants responded faster in the new task, using dynamic stimuli, compared to the standard task with static stimuli, is in line with our hypothesis. Because the stimuli were steadily and continuously moving toward each other during the trial, timing of the response could be monitored very accurately. It is likely that this extra stimulus feature increased the participants' motivation to respond as quickly as possible and maintain focused attention. This is supported by the increase in CNV amplitude, which has previously been associated with motivation and attention $[2,5]$.

Since the participants in experiment 2 were not the same as those in experiment 1 , reaction times cannot be directly compared between the two experiments. However, it is still striking that although the same stimuli were used in the Go/No-go task, responses were much slower compared to the Lines task. Responses to the 50 and $20 \%$ trials were rather close to those in the TL task. In these 'uncertain' trials additional processing related to the decision to make a response can account for this result. Response times in the $100 \%$ trials were faster compared to the TL task, but slower compared to the Lines task. This is surprising, since the $100 \%$ trials in the Go/No-go task are actually identical to the Lines task. Although participants can be sure that they will have to respond unconditionally, they are approximately twice as slow compared to the Lines task. This may partly be explained by the fact that this was a different group of participants. However, other explanations may be that inhibition in the uncertain trials spreads to the $100 \%$ Go trials or the participants did not trust the instructions. This latter explanation was given by Smith et al. [24] for the fact that participants seemed to prepare to give a response on specific No-go trials.

Table 4

Mean amplitudes (SEM) of the late CNV for the different trial types in the 9 electrode positions.

\begin{tabular}{|c|c|c|c|c|c|}
\hline Electrode & $F$ & df & $100 \%$ & $50 \%$ & $20 \%$ \\
\hline F3 & 0.992 & $1.39,26.35$ & $-7.39(1.05)$ & $-6.39(1.03)$ & $-6.20(0.91)$ \\
\hline $\mathrm{Fz}$ & 2.576 & $1.60,30.39$ & $-8.14(0.97)$ & $-7.15(1.07)$ & $-6.18(1.08)$ \\
\hline $\mathrm{F} 4$ & $5.365^{*}$ & $1.53,29.09$ & $-6.34(1.17)$ & $-4.34(0.97)$ & $-3.80(0.99)$ \\
\hline FC3 & $3.844^{*}$ & $1.51,28.64$ & $-9.73(1.14)$ & $-7.88(1.01)$ & $-7.58(0.84)$ \\
\hline $\mathrm{FCz}$ & $3.736^{*}$ & $1.44,27.27$ & $-11.91(1.26)$ & $-10.41(1.31)$ & $-9.15(1.17)$ \\
\hline FC4 & $5.188^{*}$ & $1.58,30.04$ & $-8.37(1.30)$ & $-6.75(1.11)$ & $-5.63(1.08)$ \\
\hline $\mathrm{C} 3$ & $4.486^{*}$ & $1.38,26.28$ & $-11.16(1.37)$ & $-8.72(1.17)$ & $-8.57(0.97)$ \\
\hline $\mathrm{Cz}$ & $5.956^{*}$ & $1.35,25.63$ & $-13.54(1.51)$ & $-11.10(1.21)$ & $-9.93(1.16)$ \\
\hline $\mathrm{C} 4$ & $7.026^{*}$ & $1.62,30.77$ & $-10.06(1.32)$ & $-7.84(1.17)$ & $-6.97(1.06)$ \\
\hline
\end{tabular}


Within the Go/No-go task, the most prominent differences are observed between 'certain' vs. 'uncertain' trials. Nevertheless, results of the $50 \%$ and $20 \%$ No-go trials do indicate that they were processed differently. Responses were slower to $20 \%$ trials compared to the $50 \%$ trials, perhaps indicative of stronger inhibition. In support of this idea, relatively more false alarms were produced in the $50 \%$ trials than in the $20 \%$ trials.

The size of the early CNV was positively related to the probability participants had to produce a response. As expected the task manipulation exerted the largest effect on the early CNV at frontal electrodes $[13,20]$. The late CNV on the other hand was maximal over central electrode positions, which is also in line with previous findings $[13,20]$. The effect of the manipulation was largest at these electrodes. The late CNV seemed to be lateralized to the side contralateral to the response hand, which was expected based on previous findings [30,31].

In sum, in this study, two new tasks were developed to induce a more optimal CNV wave that could possibly be used as a screening tool in future clinical-/pharmacological studies. The adaptations to the regular task proved to be successful in enhancing response preparation as indicated by higher amplitude and faster response times. The tasks' properties are thought to promote motivation and effort of subjects to optimally prepare for each trial and this makes the task especially valuable in participants who have problems sustaining attention such as elderly participants or ADHD patients. Furthermore, varying the probability that a response has to be given affects stimulus processing, response preparation and execution as reflected by the effect on the early CNV wave, the late $C N V$ wave and response times respectively. The Go/No-go CNV task presented here may lead to new insights regarding response preparation and inhibition in both clinical and non-clinical groups on or off medication.

\section{Acknowledgement}

The authors would like to thank Conny Quaedflieg for contributing to the study.

\section{References}

[1] Bares M, Rektor I, Kanovsky P, Streitova H. Cortical and subcortical distribution of middle and long latency auditory and visual evoked potentials in a cognitive (CNV) paradigm. Clinical Neurophysiology 2003;114:2447-60.

[2] Tecce JJ. Contingent negative variation (CNV) and psychological processes in man. Psychological Bulletin 1972;77:73-108.

[3] van Boxtel GJ, Brunia CH. Motor and non-motor aspects of slow brain potentials. Biological Psychology 1994;38:37-51.

[4] Walter WG, Cooper R, Aldridge VJ, McCallum WC, Winter AL. Contingent negative variation: an electric sign of sensorimotor association and expectancy in the human brain. Nature 1964;203:380-4.

[5] McCallum WC, Cooper R, Pocock PV. Brain slow potential and ERP changes associated with operator load in a visual tracking task. Electroencephalography and Clinical Neurophysiology 1988;69:453-68.

[6] Golob EJ, Starr A. Effects of stimulus sequence on event-related potentials and reaction time during target detection in Alzheimer's disease. Clinical Neurophysiology 2000;111:1438-49.

[7] Oishi M, Mochizuki Y, Du C, Takasu T. Contingent negative variation and movement-related cortical potentials in parkinsonism. Electroencephalography and Clinical Neurophysiology 1995;95:346-9.
[8] van Deursen JA, Vuurman EF, Smits LL, Verhey FR, Riedel WJ. Response speed, contingent negative variation and P300 in Alzheimer's disease and MCI. Brain and Cognition 2009;69:592-9.

[9] Amabile G, Fattapposta F, Pozzessere G, Albani G, Sanarelli L, Rizzo PA, et al. Parkinson disease: electrophysiological (CNV) analysis related to pharmacological treatment. Electroencephalography and Clinical Neurophysiology 1986;64:521-4

[10] Kratz O, Diruf MS, Studer P, Gierow W, Buchmann J, Moll GH, et al. Effects of methylphenidate on motor system excitability in a response inhibition task. Behavioral and Brain Functions 2009;5:12

[11] Linssen AM, Vuurman EF, Sambeth A, Nave S, Spooren W, Vargas G et al. Contingent negative variation as a dopaminergic biomarker: evidence from dose-related effects of methylphenidate. Psychopharmacology 2011;218:533-42.

[12] Loveless NE, Sanford AJ. Slow potential correlates of preparatory set. Biologica Psychology 1974;1:303-14.

[13] Klorman R, Bentsen E. Effects of warning-signal duration on the early and late components of the contingent negative variation. Biological Psychology 1975;3:263-75

[14] Loveless NE, Sanford AJ. The impact of warning signal intensity on reaction time and components of the contingent negative variation. Biological Psychology $1975 ; 2: 217-26$

[15] Gaillard AW. Effects of warning-signal modality on the contingent negative variation (CNV). Biological Psychology 1976;4:139-54.

[16] Weerts TC, Lang PJ. The effects of eye fixation and stimulus and response location on the contingent negative variation (CNV). Biological Psychology 1973;1:1-19.

[17] Brunia CH. Movement and stimulus preceding negativity. Biological Psychology 1988;26:165-78.

[18] Brunia CH, van Boxtel GJ. Wait and see. International Journal of Psychophysiology $2001 ; 43: 59-75$.

[19] Babiloni C, Brancucci A, Capotosto P, Romani GL, Arendt-Nielsen L, Chen AC, et al. Slow cortical potential shifts preceding sensorimotor interactions. Brain Research Bulletin 2005;65:309-16.

[20] Haagh SA, Brunia CH. Anticipatory response-relevant muscle activity, CNV amplitude and simple reaction time. Electroencephalography and Clinical Neurophysiology 1985;61:30-9.

[21] Nagai Y, Critchley HD, Featherstone E, Fenwick PB, Trimble MR, Dolan RJ. Brain activity relating to the contingent negative variation: an fMRI investigation. Neuroimage 2004;21:1232-41.

[22] Babiloni C, Brancucci A, Arendt-Nielsen L, Del Percio C, Babiloni F, PascualMarqui RD, et al. Cortical sensorimotor interactions during the expectancy of a go/no-go task: effects of painful stimuli. Behavioral Neuroscience 2004;118:925-35.

[23] Smith JL, Johnstone SJ, Barry RJ. Effects of pre-stimulus processing on subsequent events in a warned Go/NoGo paradigm: response preparation, execution and inhibition. International Journal of Psychophysiology 2006;61:121-33.

[24] Smith JL, Johnstone SJ, Barry RJ. Response priming in the Go/NoGo task: the N2 reflects neither inhibition nor conflict. Clinical Neurophysiology 2007; 118:343-55.

[25] Banaschewski T, Brandeis D. Annotation: what electrical brain activity tells us about brain function that other techniques cannot tell us - a child psychiatric perspective. Journal of Child Psychology and Psychiatry and Allied Disciplines 2007;48:415-35.

[26] Fan J, Kolster R, Ghajar J, Suh M, Knight RT, Sarkar R, et al. Response anticipation and response conflict: an event-related potential and functional magnetic resonance imaging study. Journal of Neuroscience 2007;27:2272-82.

[27] Loveless NE, Sanford AJ. Effects of age on the contingent negative variation and preparatory set in a reaction-time task. Journal of Gerontology 1974;29: 52-63.

[28] Jaskowski P, Verleger R. A clock paradigm to study the relationship between expectancy and response force. Perceptual and Motor Skills 1993;77: 163-74.

[29] Semlitsch HV, Anderer P, Schuster P, Presslich O. A solution for reliable and valid reduction of ocular artifacts, applied to the P300 ERP. Psychophysiology 1986;23:695-703.

[30] Verleger R, Paehge T, Kolev V, Yordanova J, Jaskowski P. On the relation of movement-related potentials to the go/no-go effect on P3. Biological Psychology 2006;73:298-313.

[31] Butler SR, Glass A. Asymmetries in the CNV over left and right hemispheres while subjects await numeric information. Biological Psychology 1974;2:1-16. 